\section{Ciclovías: testimonio de la ausencia de un plan integral de transporte para Valdivia}

Cycle lanes: Testimonies related to the lack of a comprehensive transport plan for Valdivia

\section{HERnÁn NeIRA*}

\section{Resumen}

Este breve estudio trata acerca del proyecto de ciclovía en la ciudad de Valdivia y la ineficiencia de la consultora contratada para construir los carriles de acuerdo a los estándares internacionales. Entre otros temas, se analiza cómo el modelo de ciclovía en Valdivia refleja una falta de conciencia en relación a la dinámica de la ciudad, su clima y las experiencias históricas de otros países en el diseño de vías exclusivas para bicicletas.

Palabras clave: bicicleta, ciclovía, Valdivia, empresa consultora.

Profesor Titular, Universidad de Santiago de Chile. Ex Profeso Titular, Universidad Austral de Chile. E-mail: hernan.neira@ usach.cl, www.neira.cl

\begin{abstract}
This brief study deals with the cycle lane project in the city of Valdivia and the inefficiency of the consultancy firm hired to construct the lanes according to international standards. Among other issues, we analize how the model of the cycle lane in Valdivia shows a lack of awareness of the city functioning, its weather and historical experiences in other countries related to the desing of sole lanes for bikes.
\end{abstract}

Key words: bike, cycle lane, Valdivia, consultancy firm.

\section{La empresa consultora}

La Secretaría de Planificación de Transporte (SECTRA) del Ministerio de Transportes y Telecomunicaciones (MTT) de la Región de los Ríos encargaron a la empresa APIA XXI Ingenieros y Arquitectos Consultores S.A. un estudio titulado Habilitación red de ciclovías Valdivia. La empresa define en estos términos el encargo:

Nov 2010. Desarrollar el diseño de ingeniería y realizar evaluación definitiva del mejoramiento de la Gestión de tránsito de la zona céntrica y una red de Ciclovías de Valdivia. [...] se desprenden los siguientes objetivos específicos: Análisis de Red de Ciclovías, definir posibles ejes que conformarán la red de Ciclovías a partir de la oferta y demanda existente

<http://www.apiaxxiiac.com/infraestructuras.pdf> Todos los vínculos fueron consultados el 21 de marzo 2013.

2 En España, a APIAXXI le fueron adjudicados, entre otros trabajos, las obras de la autopista A-8 DEL CANTÁBRICO. TRAMO NAVIA-TAPIA DE CASARIEGO. Las obras consistieron en la construcción de un tramo de autovía de 11,9 kilómetros perteneciente a la Autovía del Cantábrico A-8". Ver <www.apiaxxi. es/pdf/obra_destacada_es.pdf> 
actualmente en los principales ejes de Valdivia. Desarrollo, análisis y evaluación de alternativas de mejoramiento de la Gestión de Tránsito en la zona céntrica y red de Ciclovías. Desarrollo del diseño de ingeniería de mejoramiento de la gestión de Tránsito en la zona céntrica y de la red de Ciclovías de Valdivia. Evaluación Social del diseño de ingeniería de mejoramiento de la Gestión de Tránsito en la zona céntrica y la red de Ciclovías de Valdivia. Creación de un documento que contenga las especificaciones técnicas y de diseño". ${ }^{1}$

La consultora APIA ha realizado, entre otros negocios, la ejecución de una parte del proyecto de ingeniería de la planta desalinizadora de agua Mantoverde, encargada por la minera Angloamerican. En Chile conocemos el prontuario ambiental de Angloamerican y también el conflicto que ha mantenido con el Estado de Chile por la propiedad de Los Bronces, en la Región Metropolitana. Camiones de esa empresa o que la sirven derramaron nitrato de amonio en el río Mapocho, el 3 de marzo 2012. Asimismo, el 4 de junio 2012 un camión de la misma empresa causó la muerte de un automovilista. Angloamerican enfrenta también la oposición de la comunidad de Lo Barnechea, por los estanques de relave, que, de romperse, llegarían a las localidades situadas más abajo. ${ }^{2}$ Es posible, en consecuencia, que los intereses de algunas empresas a las que ha servido APIA XXI estén en contra de los intereses de la República de Chile. Aunque jurídicamente eso no suponga incompatibilidades, las características de la empresa y los intereses servidos por APIA XXI pueden ser un motivo importante para dudar de lo adecuado de su elección como consultor. La empresa también realizó un estudio sobre tránsito y ciclovías para La Serena y otro para La Calera.
Según la web de su matriz institucional (http://www.apiaxxiiac.com/), se trata de una empresa internacional, con sede en España, filial en Chile (entre otros países), centrada en grandes proyectos, con especialidad en la gran infraestructura minera y automovilística (autopistas, grandes puentes, etc.). En la web mencionada, no se logra constatar su especialidad en transportes livianos o medioambientalmente sustentables. Como se verá, este hecho puede ser determinante en que el informe parece no comprender algunos de los fenómenos de transporte urbanos, la ausencia de información actualizada en materia de transporte ciclístico y el desconocimiento de la ciudad de Valdivia.

\section{Ausencia de análisis de otras experiencias}

En el informe, no aparece -porque nunca se habrían consultado- antecedentes de usuarios o de otras experiencias sobre bicicletas, fallidas o exitosas, en Chile o fuera de Chile. No se entrega ninguna información sobre las demandas de los usuarios, ni tampoco de la forma como estos valoran, perciben o usan la ciudad o la bicicleta. Al respecto sólo hay algunas estadísticas de tráfico y accidentes de bicicletas. El informe omite que las causas de los "accidentes" de bicicletas son definidas de muy distinta forma según interprete los hechos un informante con criterio de automovilista o de ciclista.

Ello tiene consecuencias directas en la sección "Formulación de un plan maestro", donde se explicita que las fuentes de información principales no tuvieron en cuenta a los usuarios. No estaría de más que el zapato le pregunte al pie si le duele la horma en la que tendrá que caminar. 


\section{¿Uso actual o uso futuro?}

Los circuitos elegidos por las autoridades, a propuesta de la consultora, tienen por base los recorridos actuales de las bicicletas. Sin embargo, los recorridos actuales no son necesariamente los más deseados, sino aquellos donde hoy se puede circular en bicicleta con menor peligro de muerte. Hace falta integrar los recorridos deseados, que pueden o no coincidir con los trayectos actuales.

Se consideró también como criterio de elección los conflictos con otros medios de transporte, pero no se consideró que, si las autoridades regionales y municipales trabajaran con sentido de eficiencia, los medios de transporte -hoy dominados por el automóvil-, deberían centrarse en el transporte público. La eficiencia del transporte urbano exige que los buses vayan por vías segregadas, con las cuales deben integrarse las ciclovías. En consecuencia, los diseños propuestos por la consultora y acogidos por las autoridades de transporte regionales parten del supuesto que se mantendrá la actual tiranía del automóvil en Valdivia, no a un sistema coherente y completo de transportes, como el que se desea para la ciudad. Es una medida aislada y puntual que no plantea soluciones de fondo. Por ello, los rendimientos de las ciclovías propuestas serán menores de lo que se podría esperar del esfuerzo, que a pesar de las dificultades que describimos aquí, valoramos positivamente.

\section{Anchos y seguridad}

La tabla 13.3 muestra que el consultor ha previsto anchos totales que oscilan entre 1,5 y 1,75 metros. Eso ignora las medidas reales de una bicicleta. Muy especialmente el informe propone diseños de ciclobandas desconociendo que existen volantes de bicicleta que tienen $70 \mathrm{~cm}$ de un extremo a otro. Si dos bicicletas idénticas se encuentran en sentidos opuestos, el espacio de separación que queda entre ellas es demasiado estrecho e imposible de calcular. Eso deja a una bicicleta en la triple disyuntiva: o bien los extremos del volante chocan a los peatones que van por la acera contigua; o bien hacen salir el volante hacia donde circulan los automóviles, chocando con el espejo; o bien chocan dos bicicletas que vayan en sentido opuesto.

Una ciclovía, en sí, no es un elemento de seguridad para el ciclista cuando ha sido diseñada con desconocimiento de las bicicletas y de las necesidades físicas que tiene para llegar a ser útil. La experiencia internacional ya conoce el hecho: la ciclovía sólo es segura si tiene suficiente ancho y si está suficientemente segregada de cualquier otro vehículo (bicicletas, automóviles, peatones) (http://www.estadao. com.br/noticias/cidades,sorocaba-teve-so-1acidente-em-4-anos, 1009588,0.htm).

Además, no previó el consultor que una bicicleta tiene necesidad de adelantar. Si las ciclovías previstas tienen un éxito tan solo parcial, serán demasiado lentas para muchos que querrán usarlas para ir más rápido que en auto al trabajo. A ello se agrega el riesgo de que policías y aseguradores consideren que, por el solo hecho de existir una ciclovía -demasiado estrecha, insuficientemente segregada y lenta-, se deba circular por ella en bicicleta. Esto es inadmisible considerando lo que está previsto, en especial en las ciclobandas, pues varios de los trechos principales tienen fallos de diseño y serán riesgosas. 
En numerosos casos no está resuelto el problema de la relación entre el ciclista y el peatón, pues ambos compartirán las rampas de acceso a la calzada, como en el caso de la calle Cochrane. Además, no están bien calculadas las necesidades del peatón que circulará por la acera, al lado de la ciclobanda. Un peatón que circula por esa acera necesita una segregación de unos $30 \mathrm{~cm}$ respecto de un muro lateral y otro tanto respecto de la pista ciclística. Si el peatón, en una acera estrecha, se cruza con otro en sentido contrario, invadirá a la ciclobanda, pues no es posible comprimir a un ser humano. Por su lado, el volante de la bicicleta ocupará la vereda cuando el ciclista se encuentre con una bicicleta en sentido contrario. Habrá un conflicto frecuente entre peatones y ciclistas, como ya sucede, por ejemplo, en la ciclobanda de la calle Pedro de Valdivia, en la comuna de Ñuñoa de la Región Metropolitana. En varios segmentos, la "solución" prevista desplaza el conflicto entre automóvil y ciclista a otro entre ciclista y peatón: tal es el caso de la ciclobanda en el eje Aníbal Pinto, entre Baquedano y Santiago Bueras.

\section{Árboles, costos reales y medio ambiente}

Caso notable es la medición de impacto ambiental. Se realiza mediante un cuestionario, constituido por un centenar de preguntas, la mayoría sin pertinencia con los problemas planteados en Valdivia. El cuestionario parece copiado de una construcción minera en un desierto. Como casi todas las preguntas son impertinentes, el resultado siempre sale favorable y concluye que no hay problemas ambientales en la construcción de ciclovías. No considera un problema ambiental la eliminación de árboles. Es como preguntáramos si la construcción de las ciclovías en Valdivia genera problemas para los camellos. Como la respuesta siempre será negativa, el estudio concluye que no hay problemas ambientales, pues, efectivamente, los camellos no son afectados por una ciclovía en Valdivia (dado que no circulan camellos por la ciudad). Allí queda de manifiesto la inadecuación y escasa sensibilidad de la empresa para tratar temas relacionados con bicicletas.

Otro ejemplo de ello es que el informe considera que los árboles se pueden eliminar o sustituir (el proyecto contempla talarlos en todos los casos), por un valor de $\$ 5.000$. Eso es falso. Las probabilidades de que un árbol prenda en las calles transitadas es casi nula, incluso si se planta varias veces, porque será destruido. Los valores están infrapresupuestados en los cálculos de la consultora y que las autoridades valdivianas dan como válidos.

Como norma general, no deben eliminarse los árboles existentes, por la dificultad de que puedan ser sustituidos. ¿Dónde? No hay espacio para árboles en el diseño vial de Valdivia en las últimas décadas. Hablar de sustitución es una fantasía. De ser absolutamente imposible mantenerlos, debe presupuestarse la sustitución por un individuo de al menos 2 metros de altura sobre el suelo, con una protección metálica, riego diario desde noviembre a febrero y con replantación en al menos tres oportunidades en caso de ser destruido, a fin de asegurar el prendimiento que probablemente no alcanzará más allá del $75 \%$, incluso bajo esas condiciones de protección. El costo por árbol, por lo tanto, puede calcularse en unos $\$ 110.000$ (5 UF), veintidós veces lo que propone la consultora. En notorio que la consultora desconoce la ciudad que pretende analizar y que también lo hacen las autoridades que aceptan un informe 
tan descontextualizado. La propuesta actual contribuirá a incrementar el carácter desértico de la zona urbana de Valdivia, que se destaca, entre las ciudades de Chile, por haber eliminado los árboles de todas las vías principales, porque no les dio espacio en el diseño.

Los pocos árboles que subsisten, que provienen de diseños más antiguos, desaparecerán. Eso es todo lo contrario de lo que necesitan ciclistas y peatones, que demandan aceras y ciclovías segregadas de los automóviles por largas hileras de árboles, lo que bloquea el viento en invierno y, en verano, protege del sol.

\section{Trecho mínimos}

Una bicicleta urbana suele circular entre 15 y $25 \mathrm{~km} / \mathrm{h}$, es decir, entre 250 y $420 \mathrm{~m}$ por minuto 0 , lo que es lo mismo, entre tres veces y cinco veces la velocidad de un peatón. Un trayecto de ciclovía de 300 metros de longitud será atravesado, en promedio, en menos de un minuto por un ciclista. Si al concluir ese trayecto el ciclista se ve forzado a cruzar al otro lado, en medio de los peatones, no usará ese trayecto.

Para que el ciclista efectivamente se desvíe a la ciclovía hay que ofrecerle un nivel de continuidad que justifique la mayor distancia recorrida que si hubiera ido directamente por la calzada. Eso se consigue evitando los cambios de un lado a otro y dándole espacios que el proyecto no contempla, por trechos en lo posible de no menos de 1.000 metros (entre 2,4 y 4 minutos en bicicleta).

Ciclovías con cruces, cambios de lado forzados o intersección con peatones en menos de 1.000 metros tienen escaso uso, como lo demuestra el desafortunado ejemplo de la ciudad brasileña Curitiba. Esa ciudad figura como la segunda con más kilómetros de ciclovías en el mundo, después de Ámsterdam. Ahora bien, a diferencia de Ámsterdam, su uso es prácticamente nulo. En Curitiba, las ciclovías están principalmente en parques, con uso sólo dominguero. Las otras, a pesar de estar situadas en lugar de gran necesidad de transporte, son demasiado estrechas, carecen de suficiente distancia respecto de la acera (rua Mariano Torre), intersectan con peatones o tienen demasiados cruces (Av. Fredolin Wolf, proximidades del Passeio Publico). ¿Por qué? Porque su planificación no consultó el uso verdadero de la bicicleta y lo que hizo fue un intento de sacarla de los lugares principales (las calles más céntricas, la calzada) hacia los márgenes de ella (la acera). Numerosas organizaciones ciclísticas curitibanas han denunciado que las ciclovías de Curitiba están mal diseñadas, son peligrosas y/o no satisfacen las necesidades de los usuarios, por lo que durante años han permanecido con escaso uso. Las ciclovías que se proyectan en Valdivia, con cruces de un lado a otro y proximidad con peatones, generarán atropellos, que serán fruto necesario de ese diseño urbano. En trayectos cortos, serán escasamente usadas y tendrán, por eso mismo, un uso inferior al previsto. Además, en algunos casos, los ciclistas preferirán, incluso por seguridad, continuar circulando por la calzada. Uno de los casos más graves es el de obligar al ciclista a cruzar hacia el centro de Avenida Francia.

Asimismo, las rampas de subida y bajada a una ciclobanda son difíciles de construir de forma que no haya un pequeño escalón. Las bicicletas urbanas -que se incrementarán por ser más livianas y rápidas que las montañesas- 


\begin{tabular}{|l|c|}
\hline & $\begin{array}{c}\text { Aumento del 20\% } \\
\text { de bicicletas anual } \\
\text { Base: 1 bicicleta }\end{array}$ \\
\hline Año 1 & 1,20 \\
\hline Año 2 & 1,44 \\
\hline Año 3 & 1,73 \\
\hline Año 4 & 2,07 \\
\hline Año 5 & 2,49 \\
\hline Año 6 & 2,99 \\
\hline Año 7 & 3,58 \\
\hline Año 8 & 4,30 \\
\hline Año 9 & 5,16 \\
\hline \\
Fuente: \\
noticia/santiago/2012/11/1731-493458- \\
9-estudio-asegura-que-uso-de-bicicleta- \\
como-medio-de-transporte-en-santiago. \\
shtml
\end{tabular}

dañarán la llanta cada vez que enfrenten ese pequeño escalón. Para evitar esa dificultad, quedan dos opciones: el escalón frontal no debe ser superior a un tercio del alto de la goma (aproximadamente $1 \mathrm{~cm}$, para una bicicleta urbana); y, como norma general, se debe evitar el cruce con subidas y bajadas a la ciclobanda. Eso requiere un trabajo de mucho cuidado y la supervisión de parte de quienes comprendan las necesidades de una bicicleta.

Una medida atenuante de este problema es elevar la zona de cruce, de tal forma que la ciclobanda y la acera mantengan su nivel al cruzar una calle. Tal debe ser la solución a lo largo de todo Aníbal Pinto al cruzar con Santa María, Bulnes, La Regalona, Bennet y 8 de Octubre. Sin embargo, ni el consultor ni las autoridades tomaron en cuenta esa alternativa, lo que demuestra que no han comprendido que una ciclovía con bajadas y subidas constantes siempre será de uso limitado, a lo que se agrega que el rebaje para minusválidos en cada cruce será ocupado por bicicletas, creando una nueva fuente de conflicto.

\section{Uso actual y uso futuro}

El estudio toma en cuenta la situación actual como si fuera algo estático. No prevé ni calcula que el transporte ciclístico crece un $20 \%$ anualmente en Chile, mucho más que el transporte automovilístico, a pesar de la hostilidad de las autoridades hacia la bicicleta. Este el cuadro del incremento de uso de las bicicletas aun sin ciclovías:

En cuatro años se duplica el uso de la bicicleta; en seis se triplica; $y$ en nueve se quintuplica. Ese tiempo podría ser aun más breve si tomamos en cuenta que algunas de las ciclovías previstas incentivarán el uso de las bicicletas, pues hay trechos que parecen aceptablemente bien diseñados. Ni el estudio ni las autoridades hacen uso de los datos del incremento del uso de la bicicleta. También ignoran el caso de la ciudad brasileña de Sorocaba (en el estado de San Pablo), donde, tras cuatro años de ciclovías hechas con estándares y criterios que comprenden al ciclista, "el número de bicicletas pasó de 190 mil a 300 mil en la ciudad" (http://www.estadao.com.br/ noticias/cidades,sorocaba-teve-so-1-acidente-em-4anos, 1009588,0.htm).

\section{Integración de los sistemas de transporte}

Debido a los incentivos que las autoridades han dado al automóvil en Valdivia, no hay espacio disponible en la ciudad para transportarse. Es necesario tomar una opción que, desde el punto de vista de la eficiencia de transporte, productividad económica y salud, es el 
transporte público combinado con la bicicleta. La aceptación de la bicicleta con pleno derecho en la ciudad de Valdivia supone el rediseño total de los principales ejes viales, de forma que se integre con futuras vías segregadas para micros, tal como está previsto en San Paulo (Brasil) (http://www.estadao.com.br/noticias/ cidades, ate-vias-proprias-para-bicicleta-saoinseguras-reclamam-ciclistas-, 1009583,0. $\mathrm{htm})$. Ni el consultor ni las autoridades parecen enteradas de las y soluciones actuales relativas al transporte alternativo al automóvil y de la integración vial de la bicicleta y del transporte público.

Por ello, algunos trayectos de las ciclovías previstas requieren rediseño y la creación de vías segregadas para buses y ciclísticas, y otras para ciclistas y peatones, con exclusión o restricción para automóviles. Esto es indispensable en proximidad del centro: Chacabuco, O'Higgins, Aníbal Pinto, Camilo Henríquez, Picarte, un lado Completo de Av. Alemania y otras calles deben serpensadas sin los privilegios que en ellas tienen los automóviles y con integración de transporte público, peatones y bicicletas. Valdivia requiere compensar décadas de privilegios indebidos y subvenciones a los automóviles.

\section{Conclusión: ausencia de integración, solución a medida de los automovilistas}

El estudio para la habilitación de ciclovías en Valdivia carece de varios de los elementos técnicos indispensables para que de él se puedan sacar conclusiones definitivas sobre las rutas y características de las ciclovías que la ciudad necesita. En especial, ni en el estudio ni en las propuesta hay información sobre los usuarios; no hay opinión de especialistas en transporte ciclístico; no hay estudios comparativos sobre resultados en otras ciudades de Chile ni tampoco en el extranjero; no se prevé el crecimiento del transporte ciclístico; y no hay integración con el transporte público ni en el estudio ni en el diseño.

Se percibe incompetencia de la empresa consultora y un mal planteamiento o definición de los requerimientos por parte de las autoridades; el consultor y el mandante detectan sólo parcialmente las características del sistema de transporte que se supone promueven. Fue un error grueso no haber pedido asesoría a una ONG ciclística y colocarla como contraparte técnica por el lado del mandante.

De momento, la propuesta de ciclovías nace anticuada y reproduce un esquema obsoleto: dar a las bicicletas espacios marginales, manteniendo al automóvil como centro de la ciudad. En algunos trayectos será mejor que la situación actual, pero en otros sólo postergará la solución al transporte que requiere Valdivia.

El plan de ciclovías para Valdivia, tal como lo proponen el consultor y las autoridades, dará solución parcial y en trechos discontinuos a la circulación de bicicletas. En varios segmentos, el plan busca sacar a las bicicletas de algunos puntos de conflictos con el automóvil, lo que realiza llevándolas a los márgenes y a costa, en demasiados casos, de perjudicar el transporte peatonal y la calidad urbana de Valdivia, calidad que supone busca proteger. Hay una incomprensión completa relativa a la dificultad para que un árbol pueda desarrollarse en una vía pública en Valdivia. Tampoco considera que una de los mejores incentivos para el transporte ciclístico y peatonal es una presencia continua de árboles segregando, por un lado, a peatones y ciclistas, y, por otro, a ciclistas y automóviles. Los árboles tienen una funcionalidad clave en el 
trasporte y no son, como entiende le estudio y aceptan las autoridades, un obstáculo que haya que eliminar.

Queda, pues, pendiente la tarea de un plan integral para Valdivia que tenga como eje al transporte público, a los peatones y las bicicletas, compensando la discriminación a que las autoridades los han sometido durante las últimas décadas. ${ }^{3}$ Tal como están previstas, las ciclovías serán solución en algunos segmentos, pero en otros serán un obstáculo para alcanzar una respuesta global a las necesidades de transporte en Valdivia.

Antes de comenzar a construirlas, se hace indispensable consultar a las organizaciones ciclísticas e integrar su diseño al de vías segregadas para micros con recorridos licitados.

En Valdivia, Concertación y Alianza muestran igual torpeza populista en favor del automóvil. Esa torpeza ha disminuido notablemente los rendimientos económicos de la ciudad y ha consumido inútilmente millones de horas de sus habitantes. No hay justificación para que sucesivos gobiernos regionales y locales hayan permanecido sin abordar globalmente el tema. 